\title{
Prognostic value of circulating tumor cells detected with the CellSearch system in esophageal cancer patients: a systematic review and meta-analysis
}

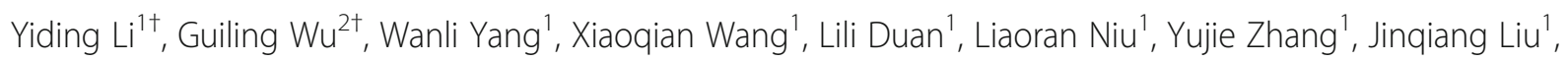
Liu Hong ${ }^{1 *}$ (D) and Daiming Fan ${ }^{1}$

\begin{abstract}
Background: Esophageal carcinoma (EC) is the seventh-most prevalent tumor in the world, which is still one of the primary causes of tumor-related death. Identifying noteworthy biomarkers for EC is particularly significant in guiding effective treatment. Recently, circulating tumor cells (CTCS) in peripheral blood (PB) were intensively discussed as prognostic markers in patients with EC. However, an ongoing controversy still exists regarding the prognostic significance of CTCs determined by the CellSearch system in EC sufferers. This meta-analysis was designed to approach this topic.

Methods: We systematically conducted searches using PubMed, Medline, Web of Science and the Cochrane Library for relevant studies, which were published through February 20, 2020. Using the random-effects model, our study was performed in Review Manager software, with odds ratios (ORs), risk ratios (RRs), hazard ratios (HRs) and 95\% confidence intervals $(\mathrm{Cls})$ as the effect values.

Results: Totally 7 articles were finally included in this study. For clinicopathological characteristics, the pooled results on TNM stage indicated that the III/IV group had higher rate of CTCs compared with the I/II group (OR=1.36, 95\% Cl: $\left.0.68-2.71, I^{2}=0 \%\right)$. Incidence of CTCs was higher in patients with T3/T4 stage (OR=2.92, 95\% Cl: $\left.1.31-6.51, I^{2}=0 \%\right)$ and distant metastasis group ( $\left.\mathrm{OR}=5.18,95 \% \mathrm{Cl}: 2.38-11.25, \mathrm{I}^{2}=0 \%\right)$ compared to patients with $\mathrm{T} 1 / \mathrm{T} 2$ stage or nonmetastatic group. The pooled analysis revealed that CTC positivity detected in EC patients was correlated with poor overall survival (OS) ( $\left.\mathrm{HR}=2.83,95 \% \mathrm{Cl}: 1.99-4.03, \mathrm{I}^{2}=0 \%\right)$ and relapse-free survival (RFS) (HR=4.71, 95\% Cl:2.73-8.13, $\left.\mathrm{I}^{2}=0 \%\right)$. When pooling the estimated $\mathrm{RR}$, a poor therapeutic response to chemoradiotherapy was discovered in patients with CTC positivity (RR $\left.=1.99,95 \% \mathrm{Cl}: 1.73-2.29, \mathrm{I}^{2}=60 \%\right)$.

(Continued on next page)
\end{abstract}

\footnotetext{
* Correspondence: hongliufmmu@163.com

${ }^{\dagger}$ Yiding Li and Guiling Wu contributed equally to this study and should be considered as co-first authors.

'State key Laboratory of Cancer Biology and National Clinical Research Center for Digestive Diseases, Xijing Hospital of Digestive Diseases, Fourth Military Medical University, 127 Changle West Road, Xi'an, Shaanxi Province 710032, PR China

Full list of author information is available at the end of the article
}

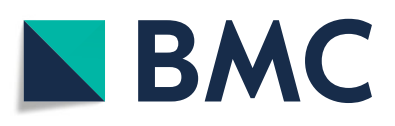

(- The Author(s). 2020 Open Access This article is licensed under a Creative Commons Attribution 4.0 International License, which permits use, sharing, adaptation, distribution and reproduction in any medium or format, as long as you give appropriate credit to the original author(s) and the source, provide a link to the Creative Commons licence, and indicate if changes were made. The images or other third party material in this article are included in the article's Creative Commons licence, unless indicated otherwise in a credit line to the material. If material is not included in the article's Creative Commons licence and your intended use is not permitted by statutory regulation or exceeds the permitted use, you will need to obtain permission directly from the copyright holder. To view a copy of this licence, visit http://creativecommons.org/licenses/by/4.0/. The Creative Commons Public Domain Dedication waiver (http://creativecommons.org/publicdomain/zero/1.0/) applies to the data made available in this article, unless otherwise stated in a credit line to the data. 
(Continued from previous page)

Conclusions: In summary, our meta-analysis demonstrated that CTCs positivity determined by the CellSearch system are correlated with the prognosis of EC patients and might indicate a poor therapeutic response to chemotherapy in EC patients.

Keywords: Circulating tumor cells, Esophageal carcinoma, Chemotherapy, Prognosis, Meta-analysis

\section{Background}

Esophageal carcinoma (EC), one of the most frequent malignant tumor, was the seventh-most prevalent tumor (572,000 new cases) and the sixth primary cause of tumor death $(509,000$ deaths $)$ in the world $[1,2]$ with a 5 -year survival rate of 18 to $25 \%$ after diagnosis [3]. The most frequent subtypes of EC are squamous cell carcinoma (SCC) and adenocarcinoma (AC) that have a high incidences in Asian countries and in Western countries, respectively [4]. Despite advances in diagnostic and therapeutic modalities against EC, locoregional recurrence and distant metastasis remain significant problems. Due to the difficulty of identifying the patients with occult metastasis, even if metastasis were not detected in patients after undergoing surgery, they may still die of tumor recurrence at an early stage [5, 6]. Currently, EC spreading or metastasis could not be detectable early by radiological and endoscopic imaging techniques. Thus, early diagnostic markers for EC are urgently needed.

An important step in tumor metastasis is that tumor cells are shed from the primary tumor to the vasculature, where they can spread to other organs. Thus, for a deeper understanding of tumor metastasis and for the earlier detection of tumors, circulating tumor cells (CTCs) which are tumor cells detached from a primary tumor and then entered into the blood circulation, have been regarded as prognostic markers. Their relevance has been investigated in several scientific research studies [7], the first of which was described in 1869 by Prof. Ashworth [8]. The results of these studies show that CTCs, as a new and effective diagnostic and prognostic biomarker, have gradually been accepted to monitor tumor recurrence and treatment effect, to determine therapeutic strategies, and to predict the survival of patients [9] because of their advantages as an earlier, more reproducible, more reliable, and accurate prognostic indicator for disease status compared with current imaging methods [10].

A considerable amount of studies have demonstrated that the CTCs presenting in the peripheral blood (PB) indicate a poor prognosis in patients with EC $[11,12]$. The withdrawal of $\mathrm{PB}$ is more convenient and less risky for patients, with comparable repeatability. With the further development of the CellSearch system, the ability to detect CTCs has become more reliable for certain metastatic tumors [13]. The CellSearch ${ }^{\circ}$ system (Menarini Silicon
Biosystems, Castel Maggiore, BO, Italy), a CTCs detection method based on immunological assay with the epithelial cell adhesion molecule (EpCAM), was placed on the market by Veridex Corporation (Warren, NJ) in 2004, which is currently the first and only FDA-approved CTCs assay for monitoring colorectal, breast, prostate tumors, etc. [14]. And the prognostic significance of CTCs determined using the CellSearch system has been summarized by previous studies in sufferers with colorectal, gastric and breast tumors [15-18]. However, an ongoing controversy exists regarding the significance of the CellSearch systemdetected CTCs in predicting the prognosis of EC patients. Thus, it requires to provide more accurately prognostic relevance based on the available data of CTCs determined by CellSearch system in EC patients.

Considering the current controversies regarding the significance of the CellSearch system-detected CTCs in prognosis of EC patients, in our study, we systematically analysed data obtained in published literatures and summed up the potential clinicopathological and prognostic significance of the CellSearch system-detected CTCs in EC patients.

\section{Methods}

\section{Search strategy}

We systematically searched PubMed, Medline, Web of Science and the Cochrane Library for relevant studies, which published through February 20, 2020. The following key words were used: "Circulating tumor cells", "CTCs", "CellSearch system" and "esophageal cancer". We used the following strategy: (((()((Esophagus tumor) OR Esophageal tumor) OR Esophageal Cancer) OR Esophagus Cancer) OR Esophagus Neoplasm) OR Esophageal Neoplasms) OR "Esophageal Neoplasms”[Mesh]) AND ((((()(“Neoplastic Cells, Circulating"[Mesh]) OR occult tumor cells) OR isolated tumor cells) OR disseminated tumor cells) OR circulating neoplastic cells) OR circulating tumor cells) OR CTC) OR circulating tumor cells detection)) AND CellSearch system.

\section{Eligibility criteria and quality assessment}

To be included in the meta-analysis, articles were selected based on the following criteria: (i) the articles only using the CellSearch system to detect CTCs and investigate the prognostic significance of CTC in EC patients; (ii) the article reported at least one noteworthy outcome indicator of CTCs, or the outcome could be calculated, 
based on data extracted from the published data; and (iii) the samples were collected from peripheral blood. Articles were excluded based on the following criteria: (i) the article was published in languages other than English; (ii) the number of EC patients and samples was less than 10; (iii) samples were collected from lymph nodes, bone marrow, or the abdominal cavity; (iv) nonhuman experiments; (v) reviews, case reports, comments, letters, and meeting records; (vi) EC and CTCs were not studied; and (vii) unable to obtain enough data through article reports and data calculations.

We evaluated the quality of the included literature with the Newcastle-Ottawa Scale (NOS), recommended by the Cochrane Library [19], according to three categories: (i) study group selection; (ii) comparability of groups; and (iii) outcome of interest. The full score was 9, and 1-4 points indicated low-quality, while 5-9 points were considered high-quality.

\section{Data extraction}

Two reviewers independently used a standardized form to extract the data from the included studies: first author's name, publication year, country of patients, characteristics of patients (number, sex, age), sampling time, detection markers, detection rate, histology, prognostic value, hazard ratio (HR) and disease control rate (DCR) of chemotherapy, and any disputes or differences were settled by a third independent investigator. For studies with multiple arms, each arm was considered an independent data set. The tumors DCR were evaluated in accordance with the Response Evaluation Criteria in Solid Tumors (RECIST) guideline [20]. The DCR is calculated as (complete response $[\mathrm{CR}]+$ partial response $[\mathrm{PR}]+$ stable disease $[\mathrm{SD}]$ )/ (complete response $[\mathrm{CR}]+$ partial response $[\mathrm{PR}]+$ stable disease $[\mathrm{SD}]+$ progressive disease $[\mathrm{PD}]$ ).

\section{Statistical analysis}

We used Review Manager software (RevMan, version 5.3, The Nordic Cochrane Centre, The Cochrane Collaboration, London, UK) to analyze the data in our metaanalysis. The estimated odds ratios (ORs) from the included studies were used to assess the association between CTC detection and different clinicopathologic features of EC. To statistically assess the prognostic effects of CTCs, we extracted the HR and 95\% confidence interval (CI) of overall survival (OS) and relapse-free survival (RFS) from the included studies. If HRs, 95\% CIs, or P-values were not directly provided in the
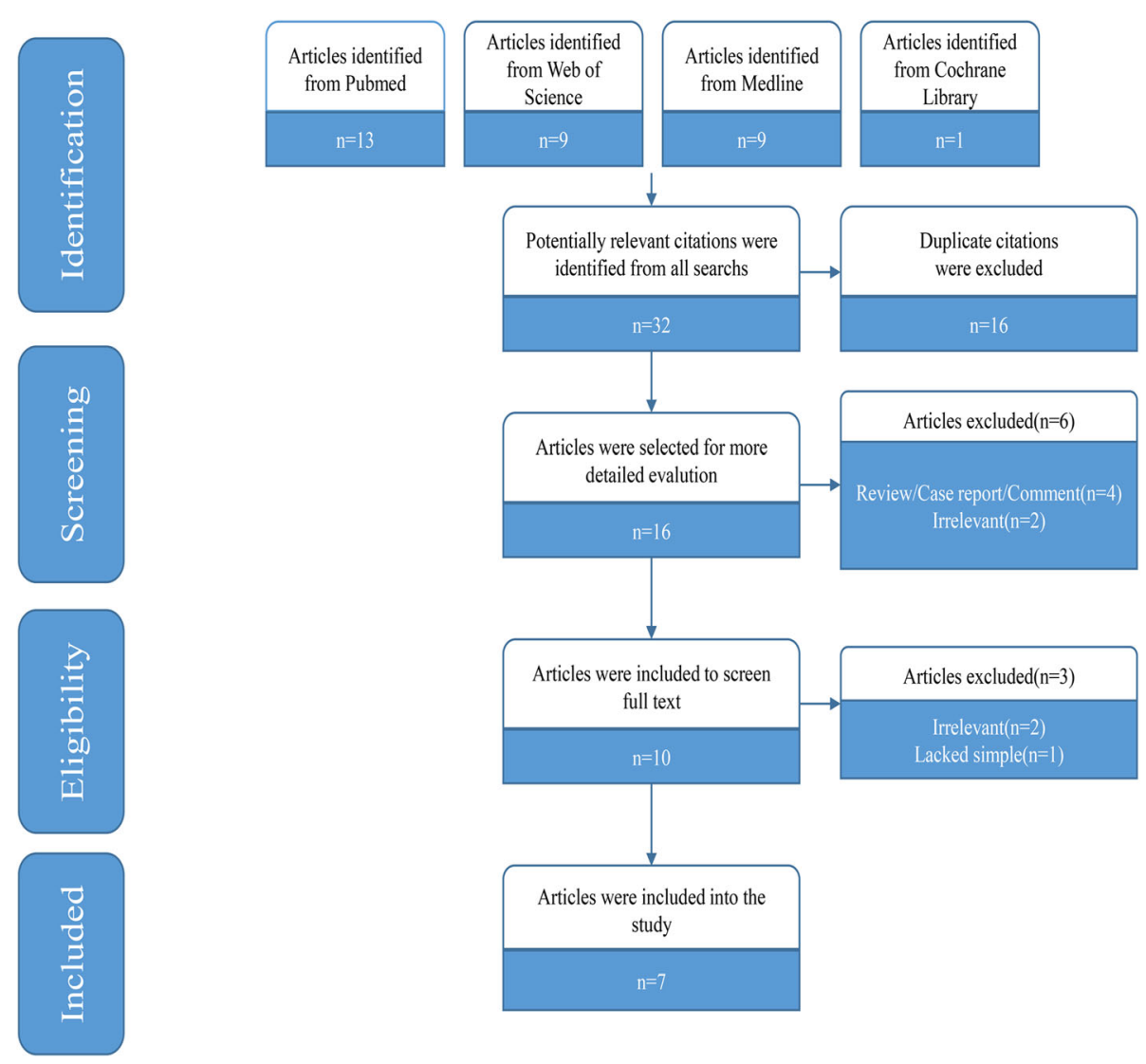

Fig. 1 Flow chart of study selection 
original literature, the estimated HR was used to assess prognostic effects based on the method described by Tierney et al. [21], and HR $>1$ reflects further disease progression or more deaths in the patients with CTC positivity. Furthermore, the estimated risk ratio (RR) was calculated to assess the DCR. We pooled the extracted HRs together in Review Manager. All statistical values were combined with 95\% CIs, and all P values were two sided whose threshold was considered statistically significant when it was less than 0.05 . Heterogeneity among the studies was tested using Cochran $\mathrm{Q}$ test and $\mathrm{I}^{2}$ statistic. Significant heterogeneity was considered when $\mathrm{P} \leq$ 0.1 or $\mathrm{I}^{2} \geq 50 \%$ [22], and in these cases, a random-effects model was used. Simultaneously, according to the differences in the data retrieved, subgroup analyses were performed, such as for the age of patients, sex of patients, histology, and clinicopathological significance. Publication bias was evaluated using a funnel plot.

\section{Results}

\section{Study characteristics}

The initial search yielded 32 records in PubMed, Medline, Web of Science and the Cochrane Library. Of these, 16 duplicate studies were excluded. We excluded 6 records after reading the titles and abstracts. After reviewing the full texts, 7 articles were finally included in this study [11, 12, 23-27]. The selection flowchart of this study is shown in Fig. 1.

In total, 7 studies (ranging from 2008 to 2019) from Asia and Europe (Japan, Germany, and UK) including 8 sets of data, which comprised 405 EC patients were included (sample size median: 45(18-100), mean: 58; CTC-positive patient rate median: 19.7\%(13.2-50\%)) (Table 1). Based on the sampling time points, 5 studies $[11,12,25-27]$ only evaluated CTCs at baseline and two studies [23, 24] evaluated CTCs both at baseline and intra-therapy. HRs for OS was provided in 8 sets of data from 7 studies [11, 12, 23-27], and RFS in 3 sets of data from 3 studies [11, 12, 25], respectively.

\section{Quality assessment}

Among the 7 studies included: 2 studies [26, 27] were of low quality and the other 5 studies [11, 12, 23-25] were of high quality, evaluated based on the NOS (Table 2).

\section{Diagnosis}

\section{CTC detection and clinicopathological features}

We extracted and analyzed clinicopathological variables from the included articles in our meta-analysis when they were mentioned in at least 3 studies. The results of the pooled ORs of the parameters of EC patients, which were used to evaluated the potential correlations between the detection of CTCs and clinicopathological

Table 1 Characteristics of included studies for the meta-analyses

\begin{tabular}{|c|c|c|c|c|c|c|c|c|c|c|c|c|c|}
\hline \multirow[t]{2}{*}{ Reference } & \multirow[t]{2}{*}{ Year } & \multirow[t]{2}{*}{ Country } & \multicolumn{2}{|l|}{ Patient } & \multirow{2}{*}{$\begin{array}{l}\text { Age } \\
\text { (years) }\end{array}$} & \multirow{2}{*}{$\begin{array}{l}\text { Tumor } \\
\text { stage }\end{array}$} & \multirow{2}{*}{$\begin{array}{l}\text { Sampling } \\
\text { time }\end{array}$} & \multirow{2}{*}{$\begin{array}{l}\text { Target antigen/ } \\
\text { gene }\end{array}$} & \multirow[t]{2}{*}{ Cutoff } & \multicolumn{2}{|c|}{ Positive } & \multirow{2}{*}{$\begin{array}{l}\text { End } \\
\text { point }\end{array}$} & \multirow{2}{*}{ Treatment regimens } \\
\hline & & & number & $\begin{array}{l}\text { male/ } \\
\text { female }\end{array}$ & & & & & & $n$ & $\begin{array}{l}\text { male/ } \\
\text { female }\end{array}$ & & \\
\hline $\begin{array}{l}\text { Konczalla L } \\
11\end{array}$ & 2019 & Germany & 76 & $27 / 19$ & $65(N R)$ & $\mathrm{I}-\mathrm{IV}$ & Baseline & $\mathrm{CK}, \mathrm{CD} 45$ & $\begin{array}{l}\geq 1 / \\
7.5 \mathrm{ml}\end{array}$ & 15 & $10 / 5$ & $\begin{array}{l}\text { OS/ } \\
\text { RFS }\end{array}$ & Surgery \\
\hline $\begin{array}{l}\text { Woestemeier } \\
\text { A } 12\end{array}$ & 2018 & Germany & 45 & $35 / 10$ & 63.3 & $|-|||$ & Baseline & $\begin{array}{l}\text { EpCAM, CK (8, } \\
18,19), \text { CD45 }\end{array}$ & $\begin{array}{l}\geq 1 / \\
7.5 \mathrm{ml}\end{array}$ & 7 & $6 / 1$ & $\begin{array}{l}\text { OS/ } \\
\text { RFS }\end{array}$ & Surgery \\
\hline \multirow[t]{2}{*}{ Tanaka M 23} & 2015 & Japan & 38 & $30 / 8$ & $\begin{array}{l}63 \\
(43- \\
87)\end{array}$ & $\mathrm{I}-\mathrm{IV}$ & Baseline & $\begin{array}{l}\text { EpCAM, CK (8, } \\
18,19), \text { CD45 }\end{array}$ & $\begin{array}{l}\geq 2 / \\
7.5 \mathrm{ml}\end{array}$ & 19 & $14 / 5$ & OS & $\begin{array}{l}\text { Chemotherapy/ } \\
\text { Chemoradiotherapy }\end{array}$ \\
\hline & & & 38 & $30 / 8$ & $\begin{array}{l}63 \\
(43- \\
87)\end{array}$ & $\mathrm{I}-\mathrm{IV}$ & $\begin{array}{l}\text { intra- } \\
\text { therapy }\end{array}$ & $\begin{array}{l}\text { EpCAM, CK }(8 \\
18,19), \text { CD45 }\end{array}$ & $\begin{array}{l}\geq 2 / \\
7.5 \mathrm{ml}\end{array}$ & 15 & NR & OS & \\
\hline \multirow[t]{2}{*}{$\begin{array}{l}\text { Matsushita D } \\
24\end{array}$} & 2015 & Japan & 90 & $78 / 12$ & $\begin{array}{l}65 \\
(46- \\
98)\end{array}$ & $\|-I V$ & Baseline & EpCAM, CD45 & $\begin{array}{l}\geq 1 / \\
7.5 \mathrm{ml}\end{array}$ & 25 & $22 / 3$ & OS & $\begin{array}{l}\text { Chemotherapy/ } \\
\text { Chemoradiotherapy }\end{array}$ \\
\hline & & & 71 & $N R$ & NR & $N R$ & $\begin{array}{l}\text { intra- } \\
\text { therapy }\end{array}$ & EpCAM, CD45 & $\begin{array}{l}\geq 1 / \\
7.5 \mathrm{ml}\end{array}$ & 15 & NR & NR & \\
\hline Reeh M 25 & 2015 & Germany & 100 & $77 / 23$ & $\begin{array}{l}66 \\
(32- \\
85)\end{array}$ & $\mathrm{I}-\mathrm{IV}$ & Baseline & $\begin{array}{l}\text { EpCAM, CK, } \\
\text { CD45 }\end{array}$ & $\begin{array}{l}\geq 1 / \\
7.5 \mathrm{ml}\end{array}$ & 18 & $13 / 5$ & $\begin{array}{l}\text { OS/ } \\
\text { RFS }\end{array}$ & Surgery \\
\hline Sclafani F 26 & 2014 & U.K. & 18 & $16 / 2$ & $\begin{array}{l}61 \\
(38- \\
78)\end{array}$ & $N R$ & Baseline & $\begin{array}{l}\text { EpCAM, CK } \\
\text { CD45 }\end{array}$ & $\begin{array}{l}\geq 2 / \\
7.5 \mathrm{ml}\end{array}$ & 8 & NR & OS & $N R$ \\
\hline Hiraiwa K 27 & 2008 & Japan & 38 & $N R$ & $N R$ & $N R$ & Baseline & $\begin{array}{l}\text { EpCAM, CK } \\
\text { CD45 }\end{array}$ & $\begin{array}{l}\geq 2 / \\
7.5 \mathrm{ml}\end{array}$ & 5 & NR & OS & Chemotherapy \\
\hline
\end{tabular}


Table 2 The assessment of the risk of bias in included studies using the Newcastle-Ottawa scale

\begin{tabular}{|c|c|c|c|c|c|c|c|c|c|c|c|}
\hline \multirow[t]{2}{*}{ Study } & \multirow[t]{2}{*}{ Year } & \multicolumn{4}{|c|}{ Selection (0-4) } & \multicolumn{2}{|c|}{ Comparability (0-2) } & \multicolumn{3}{|c|}{ Outcome (0-3) } & \multirow[t]{2}{*}{ Tota } \\
\hline & & REC & SNEC & $\mathrm{AE}$ & DO & SC & $\mathrm{AF}$ & $\mathrm{AO}$ & FU & AFU & \\
\hline Konczalla L & 2019 & 1 & 1 & 1 & 1 & 0 & 0 & 1 & 1 & 0 & 6 \\
\hline Woestemeier A & 2018 & 1 & 1 & 1 & 1 & 0 & 0 & 1 & 1 & 0 & 6 \\
\hline Tanaka M & 2015 & 1 & 1 & 1 & 1 & 0 & 0 & 1 & 1 & 1 & 7 \\
\hline Matsushita D & 2015 & 1 & 1 & 1 & 1 & 0 & 0 & 1 & 1 & 0 & 6 \\
\hline Reeh M & 2015 & 1 & 1 & 1 & 1 & 0 & 0 & 1 & 1 & 0 & 6 \\
\hline Sclafani F & 2014 & 1 & 1 & 0 & 1 & 0 & 0 & 1 & 0 & 0 & 4 \\
\hline Hiraiwa K & 2008 & 1 & 1 & 0 & 1 & 0 & 0 & 1 & 0 & 0 & 4 \\
\hline
\end{tabular}

Abbreviations: REC Representativeness of the exposed cohort, SNEC Selection of the nonexposed cohort, AE Ascertainment of exposure, DO Demonstration that outcome of interest was not present at start of study, SC Study controls for age, sex, AF Study controls for any additional factors (chemoradiotherapy, curative resection), $A O$ Assessment of outcome, FU Follow-up long enough ( $36 \mathrm{M}$ ) for outcomes to occur, AFU Adequacy of follow-up of cohorts ( $\geq 90 \%$ ). "1" means that the study is satisfied the item and " 0 " means the opposite situation

parameters, are summarized in Table 3. We extracted and analyzed eight clinicopathological features according to the criteria mentioned above. No significant differences in the results of CTC detection was observed based on age $\left(\mathrm{OR}=1.0795 \% \mathrm{CI}\right.$ : $\left.0.62-1.87, \mathrm{I}^{2}=0 \%\right)$ and $\operatorname{sex}\left(\mathrm{OR}=1.01,95 \% \mathrm{CI}: 0.53-1.91, \mathrm{I}^{2}=0 \%\right)$. However, for other clinicopathological parameters, incidence of CTCs was higher among patients with T3/T4 stage $\left(\mathrm{OR}=2.92,95 \% \mathrm{CI}: 1.31-6.51, \mathrm{I}^{2}=0 \%\right)$ and distant metastasis group (OR $\left.=5.18,95 \% \mathrm{CI}: 2.38-11.25, \mathrm{I}^{2}=0 \%\right)$ compared to patients with $\mathrm{T} 1 / \mathrm{T} 2$ stage or nonmetastatic group. Similarly, the pooled results on TNM stage indicated that III/IV group had higher incidence of CTCs compared with I/II group $(\mathrm{OR}=1.36,95 \% \mathrm{CI}$ : $\left.0.68-2.71, \mathrm{I}^{2}=0 \%\right)$. However, the correlation between the incidence of CTCs and clinical stage was only discussed in three included articles with 221 patients and among them 40 are CTCs-positive. Besides, the studies by Woestemeier A [12] provided the limited data of patients with stage I-III. Therefore, although the results indicated there was no significance of this difference between patients with stage I-II and those with stage III-

Table 3 Results of association between CTCs and clinicopathological characteristics

\begin{tabular}{llll}
\hline & OR $(95 \% \mathrm{Cl})$ & $\mathrm{N}$ & $P$-value \\
\hline Age: $>$ 65 vs. $\leq 65(\mathrm{OR})$ & $\left.1.07(0.62,1.87)\right|^{2}=0 \%$ & 4 & 0.8 \\
Sex: male vs. female (OR) & $\left.1.01(0.53,1.91)\right|^{2}=0 \%$ & 5 & 0.98 \\
Histology: AC vs. SCC & $\left.1.86(0.81,4.26)\right|^{2}=0 \%$ & 4 & 0.14 \\
pT: T3/T4 vs. T1/T2(OR) & $\left.2.92(1.31,6.51)\right|^{2}=0 \%$ & 3 & 0.009 \\
LN $^{3}$ vs. LN [2](OR) & $\left.1.06(0.61,1.86)\right|^{2}=0 \%$ & 4 & 0.83 \\
pM:M1 vs. MO(OR) & $5.18(2.38,11.25) I^{2}=0 \%$ & 4 & $<0.001$ \\
Stage: III/IV vs. I/II (OR) & $1.36(0.68,2.71) I^{2}=0 \%$ & 3 & 0.38
\end{tabular}

\section{OR Odds ratio}

$P$-value for estimates of $\mathrm{OR}$

"-": not available

LN Lymph node
IV $(\mathrm{P}=0.38)$, with more patients and studies included in the future, the results might suggest significant difference between different clinical status and stages. Interestingly, the AC group had higher incidence of CTCs compared with the SCC group $(\mathrm{OR}=1.86,95 \% \mathrm{CI}$ : $\left.0.81-4.26, \mathrm{I}^{2}=0 \%\right)$.

\section{CTC detection and prognosis}

To analyse the survival of EC patients, we extracted 8 studies that provided data for OS with 443 samples and 3 studies for RFS with 221 samples. When pooling the HR for OS, an association was observed between CTCpositive status detected in EC patients and poor prognosis for OS, and no significant heterogeneity among these studies was found (HR $=2.83,95 \%$ CI: 1.99-4.03, $\mathrm{I}^{2}=$ $0 \%)$. The results are shown in Fig. 2a. As shown in Fig. $2 \mathrm{~b}$, the pooled results showed that an association was observed between CTC detection in EC patients and poor prognosis indicated by RFS $(\mathrm{HR}=4.71,95 \% \mathrm{CI}$ : $2.73-8.13, \mathrm{I}^{2}=0 \%$ ).

Furthermore, we performed subgroup analyses according to the differences in the variables (publication year, country, patients' number, sampling time, cut-off value, CTC positive rate, and quality of the articles). The results are shown in Table 4. The median publication years of the included studies for OS and RFS were 2015 and 2018, respectively. The median number of patients in the OS and RFS studies was 41.5 and 76, respectively. The median positive rates of the patients in the OS and RFS studies were 23.8 and $18 \%$, respectively. The summary analysis results demonstrated significance of CTC positivity as a remarkable prognostic indicator of OS and RFS in most subgroups.

\section{CTC detection and DCR}

Only 2 studies assessed the association between incidence of CTCs and DCR in patients receiving 


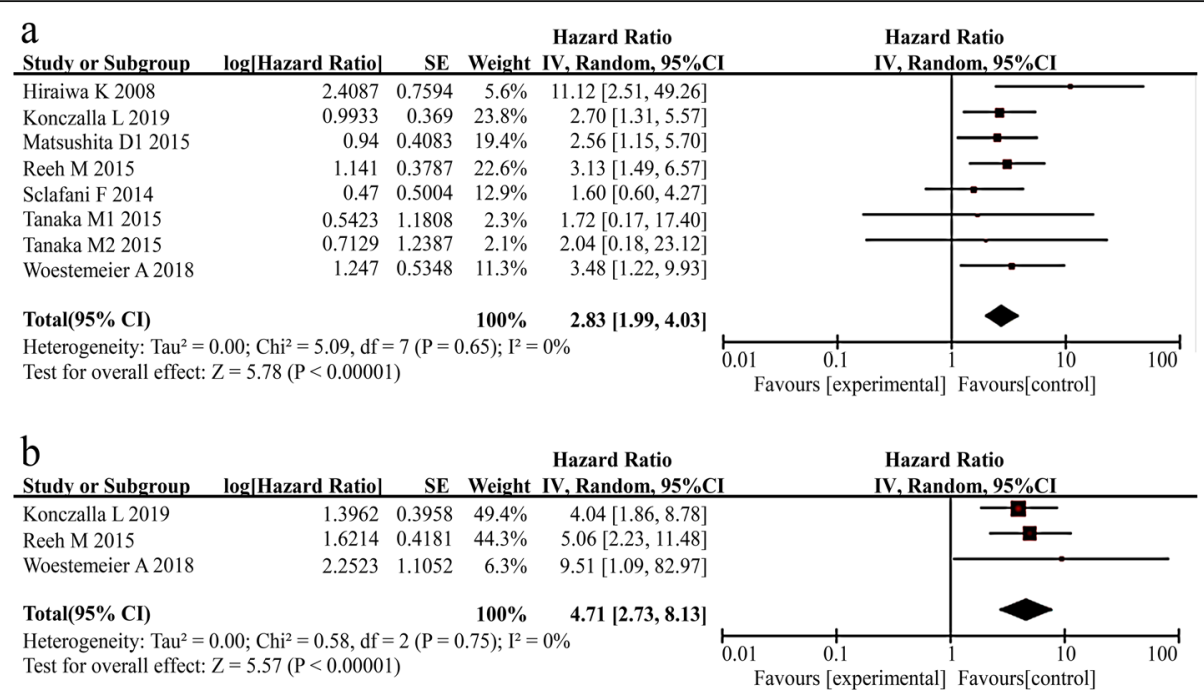

Fig. 2 Estimated hazard ratios (HR) summary for OS (a) and RFS (b). a HR for OS with CTC detection. b HR for RFS with CTC detection

Table 4 Results of subgroup analyses on OS and RFS

\begin{tabular}{|c|c|c|c|c|c|c|c|c|c|c|}
\hline \multirow[t]{2}{*}{ Variable } & \multicolumn{5}{|c|}{ OS } & \multicolumn{5}{|c|}{ RFS } \\
\hline & $\mathrm{n}$ & HR (95\% Cl) & $P$-value ${ }^{a}$ & $1^{2}$ & $P$-value & $\mathrm{n}$ & HR (95\% Cl) & $P$-value ${ }^{a}$ & $1^{2}$ & $P$-value ${ }^{b}$ \\
\hline \multicolumn{11}{|l|}{ Year $^{c}$} \\
\hline > Median & 2 & $2.93(1.62,5.31)$ & $<0.001$ & $0 \%$ & 0.7 & 1 & $4.04(1.86,8.78)$ & $<0.001$ & - & - \\
\hline$\leq$ Median & 6 & $2.78(1.79,4.30)$ & $<0.001$ & $0 \%$ & $43 \%$ & 2 & $5.48(2.54,11.79)$ & $<0.001$ & $0 \%$ & 0.59 \\
\hline \multicolumn{11}{|l|}{ Country } \\
\hline East Asia & 4 & $3.34(1.58,7.09)$ & 0.002 & $12 \%$ & 0.33 & 0 & - & - & - & - \\
\hline non-East Asia & 4 & $2.68(1.76,4.08)$ & $<0.001$ & $0 \%$ & 0.69 & 3 & $4.71(2.73,8.13)$ & $<0.001$ & $0 \%$ & 0.75 \\
\hline \multicolumn{11}{|l|}{ Patient no. ${ }^{d}$} \\
\hline >Median & 4 & $2.89(1.93,4.31)$ & $<0.001$ & $0 \%$ & 0.96 & 1 & $5.06(2.23,11.48)$ & $<0.001$ & - & - \\
\hline$\leq$ Median & 4 & $2.89(1.03,8.13)$ & 0.04 & $37 \%$ & 0.19 & 2 & $4.45(2.15,9.24)$ & $<0.001$ & $0 \%$ & 0.47 \\
\hline \multicolumn{11}{|l|}{ Sampling time } \\
\hline Baseline & 7 & $2.85(2.00,4.07)$ & $<0.001$ & $0 \%$ & 0.54 & 3 & $4.71(2.73,8.13)$ & $<0.001$ & $0 \%$ & 0.75 \\
\hline intra-therapy & 1 & $2.04(0.18,23.12)$ & 0.56 & - & - & 0 & - & - & - & - \\
\hline \multicolumn{11}{|l|}{ Cutoff value } \\
\hline$\geq 1 / 7.5 \mathrm{ml}$ & 4 & $2.89(1.93,4.31)$ & $<0.001$ & $0 \%$ & 0.96 & 3 & $4.71(2.73,8.13)$ & $<0.001$ & $0 \%$ & 0.75 \\
\hline$\geq 2 / 7.5 \mathrm{ml}$ & 4 & $2.89(1.03,8.13)$ & 0.04 & $37 \%$ & 0.19 & 0 & - & - & - & - \\
\hline \multicolumn{11}{|l|}{ Positive rate ${ }^{e}$} \\
\hline >Median & 4 & $2.09(1.17,3.74)$ & 0.01 & $0 \%$ & 0.91 & 1 & $4.04(1.86,8.78)$ & $<0.001$ & - & - \\
\hline$\leq$ Median & 4 & $3.38(2.17,5.26)$ & $<0.001$ & $0 \%$ & 0.41 & 2 & $5.48(2.54,11.79)$ & $<0.001$ & $0 \%$ & 0.59 \\
\hline \multicolumn{11}{|l|}{ Quality } \\
\hline High & 7 & $2.61(1.82,3.75)$ & $<0.001$ & $0 \%$ & 0.95 & 3 & $4.71(2.73,8.13)$ & $<0.001$ & $0 \%$ & 0.75 \\
\hline Low & 1 & $11.12(2.51,49.26)$ & - & - & 0.17 & 0 & - & - & - & - \\
\hline Overall & 8 & $2.83(1.99,4.03)$ & $<0.001$ & $0 \%$ & 0.65 & 3 & $4.71(2.73,8.13)$ & $<0.001$ & $0 \%$ & 0.75 \\
\hline
\end{tabular}

a $P$-value for estimates of HR.

${ }^{b} P$-value for heterogeneity

' The median year of Os and PFs was 2015 and 2018, respectively

${ }^{\mathrm{d}}$ The median patient number of Os and PFs was 41.5 and 76 , respectively

${ }^{\mathrm{e}}$ The median positive rate of Os and PFs was 23.8 and $18 \%$, respectively

"-": not available 
chemotherapy/chemoradiotherapy, and the overall response rate (ORR) was used to assess the response to chemoradiotherapy. When pooling the estimated RR, CTC-positive patients had a poor response to chemoradiotherapy compared with CTC-negative patients $(\mathrm{RR}=$ 1.99, 95\% CI: $1.73-2.29, \mathrm{I}^{2}=60 \%$ ), as shown in Fig. 3.

\section{Subgroup analysis and publication bias}

Regarding the heterogeneity of the pooled survival effects, there was no statistical significance in betweenstudy heterogeneity for OS and RFS. We used funnel plots to detect publication bias, as shown in Fig. 4. In all comparisons, shape of the funnel plots had a symmetrical distribution. Thus, no significant publication bias was found in the meta-analyses of OS and RFS.

\section{Discussion}

Although the advanced treatment have been widely adopted in EC patients recently, the presence of spreading and recrudescence of EC are still great challenges for both surgeons and patients [3,28]. Due to late diagnosis and limited treatment options, most EC patients have a poor prognosis and high mortality. To prompt timely diagnosis and treatment, biomarkers to determine the recurrent or metastatic status of $\mathrm{EC}$ are in great request. Recently, CTCs, detached cells from a primary tumor in $\mathrm{PB}$, have been increasingly investigated for their prognostic value in many tumors. As described in the "seed and soil" theory [29], CTCs are regarded as critical factors for tumors metastasis [30]. As demonstrated in many studies, high CTCs was associated with the poor survival in many solid tumours, such as breast cancer [31], bladder cancer [32], ovarian cancer and gastric cancer [33, 34]. In addition, due to its benefits of time and cost saving, easy operation and higher specificity and reproducibility, CTC detection from PB can be regarded as an effective evaluation tool for monitoring and assessing treatment effects in EC patients. For EC, several previously published meta-analyses demonstrated the prognostic value of CTCs; however, the assays used to detect CTCs were predominately restricted to polymerase chain reaction (PCR) and immunocytochemistry (ICC) in the included studies [35]. Interestingly, the clinical utility of CTC detection with the CellSearch system from the PB of EC patients has been demonstrated in several studies [11, 12, 23-27]. Thus, to quantitatively assess the clinical value of CTCs determined using the CellSearch system in EC patients is valuable. It is commonly acknowledged that CTCs detected using CellSearch system are EpCAM ${ }^{\text {high }}$, and $\mathrm{EpCAM}^{\text {low }}$ CTCs might be missed due to epithelial-mesenchymal transition (EMT). Researchers have described a method to collect EpCAM ${ }^{\text {low }}$ CTCs using immunomagnetic ways to deplete EpCAM ${ }^{\text {high }}$ cells, which is favorable for investigating the correlation between $\mathrm{EpCAM}^{\text {low }} \mathrm{CTCs}$ and clinical outcomes of patients [36-38]. Results from a pilot study in patients with metastatic lung cancer did not indicate any significant association between the incidence of EpCAM ${ }^{\text {low }}$ CTCs and overall survival (OS). Similar results were found in a research including 97 metastatic non-small-cell lung cancer patients. In other types of cancers such as prostate cancer and breast cancer, the incidence of $\geq 5$ EpCAM $^{\text {low }}$ CTCs was not significantly associated with prognosis of patients, contrary to the presence of $\geq 5 \mathrm{EpCAM}^{\text {high }}$. Additionally, previous study also indicated that EpCAM ${ }^{\text {high }}$ CTCs from colorectal cancer approximately account for 89\% [39], which indicates the numbers of CTCs detected with CellSearch system were more than the missed EpCAM $^{\text {low }}$ CTCs, and correspondingly the significance of $\mathrm{EPCAM}^{\text {high }}$ CTCs were higher. Collectively, these studies all suggested that although CTCs with a mesenchymal phenotype may not be detected by the CellSearch system, obvious significance of EpCAM ${ }^{\text {low }}$ CTCs in predicating prognosis in cancer patients was not indicated.

As far as we know, this is the first meta-analysis that focused on the significance of CTC determined only using the CellSearch system in EC. As a result, our results are more informative than those of previous studies. Our meta-analysis of 7 articles including 405 EC patients indicating that CTC-positive patients have poorer OS and RFS compared with CTC-negative patients, which showed that the detection of CTCs has clinicopathological and prognostic value in patients with EC. Moreover, the results of summary analysis demonstrated the significance CTC positivity as a remarkable prognostic indicator of OS and RFS in most subgroups. When pooling the HR for OS, CTC-positive status

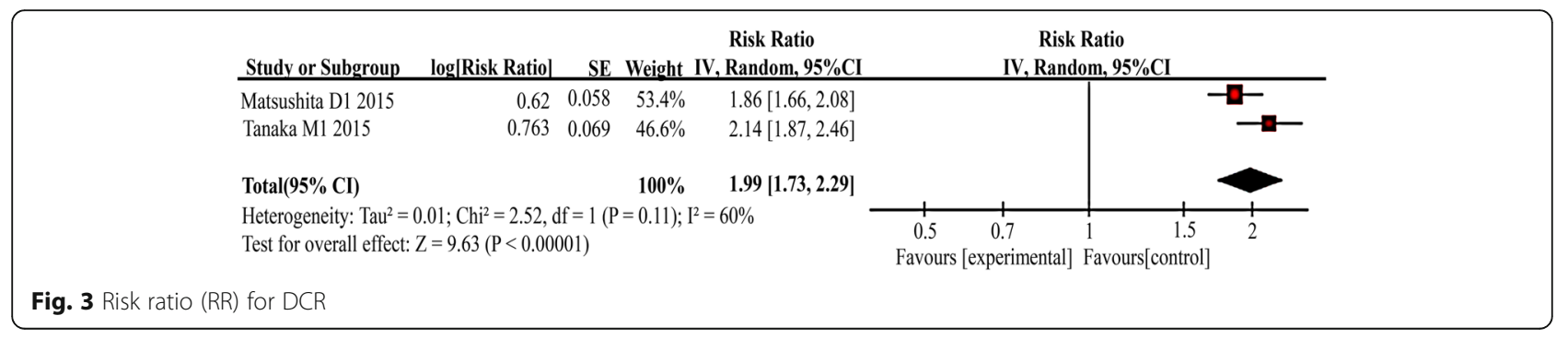



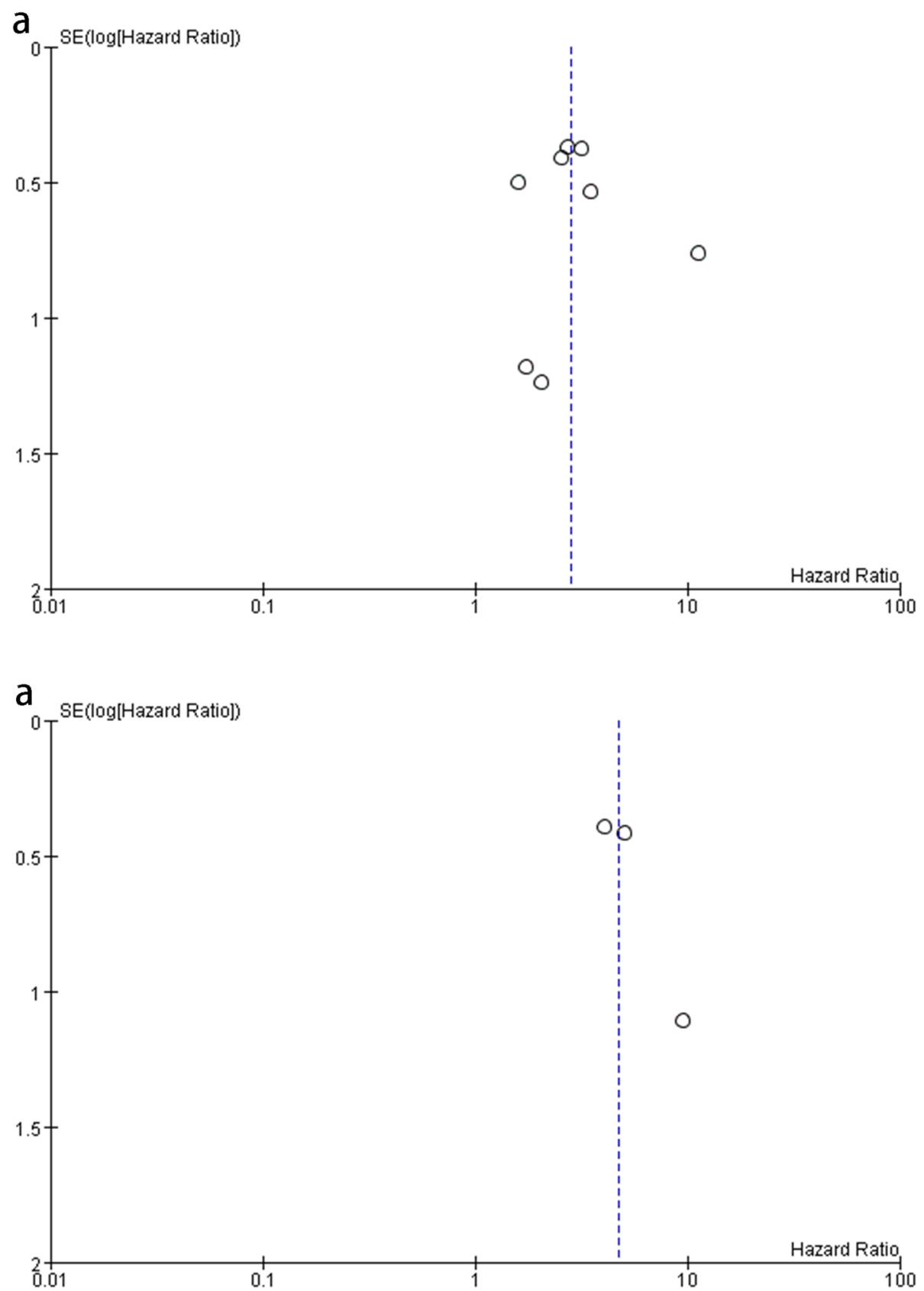

Fig. 4 Assessment of publication bias using Funnel plot analysis. a Funnel plot analysis of studies on OS. b Funnel plot analysis of studies on RFS. Publication bias was not found in the meta-analyses of OS and RFS

detected in EC patients was correlated with poor OS $\left(\mathrm{HR}=2.83,95 \% \mathrm{CI}: 1.99-4.03, \mathrm{I}^{2}=0 \%\right)$ and DFS $(\mathrm{HR}=$ 4.71, 95\% CI: 2.73-8.13, $\mathrm{I}^{2}=0 \%$ ). Patients with CTC positivity have a worse prognosis than those with CTC negativity. Moon DH suggested that although CTCs detected with the CellSearch system are an independent prognostic marker, it remains to be elucidated whether they can be considered a predictive marker for therapy [40]. However, Riethdorf S indicated that the dynamic monitoring of CTCs with the CellSearch system might help to predict therapeutic efficacy in cancer [41]. Then, we extracted data and analysed the DCR of chemotherapy in patients with $\mathrm{EC}$, and the pooled analysis demonstrated that the DCR of the CTC positivity was lower than that of the CTC negativity ( $R R=1.99$, 95\% CI:1.73$2.29, \mathrm{I}^{2}=60 \%$ ). Because CTCs could more likely escape from the primary tumour and enter into peripheral blood when the biological control by the primary tumour was not functioning and internal milieu altered, tumour recurrence after surgical treatment was more 
likely to appear in CTC-positive patients [42]. Therefore, CTC detection can be regarded as an effective evaluation tool for assessing chemoradiotherapy efficacy and monitoring tumor recurrence in many solid tumors [43-45], including EC. Moreover, our meta-analysis demonstrated that CTC positivity was remarkably correlated with TNM staging, $\mathrm{pT}$ category, and distant metastasis. EC patients with stage III-IV have higher CTCsincidence than patients with stage I-II $(\mathrm{OR}=1.36)$. However, the correlation between the incidence of CTCs and clinical stage was only discussed in three included articles with 221 patients and among them 40 are CTCspositive. Besides, the studies by Woestemeier A [12] provided the limited data of patients with stage I-III. Therefore, although the results indicated there was no significance of this difference between patients with stage I-II and those with stage III-IV $(P=0.38)$, with more patients and studies included in the future, the results might suggest significant difference between different clinical status and stages. Interestingly, the AC group had a notably higher incidence of CTCs compared with the SCC group (OR $=1.86,95 \%$ CI: $0.81-4.26, \mathrm{I}^{2}=$ $0 \%)$ the results is not obviously significant $(P=0.14)$, which is consistent with other studies [11]. Besides, studies concerning the relative aggressive behavior of AC group and SCC group is rare. And it is relatively difficult to discuss the correlation between the higher incidence of CTCs and aggressive behavior in AC and SCC group, respectively. In summary, the pooled results indicate that the CTCs determined by the CellSearch system have important clinical value in assessing the prognosis of EC patients, guiding treatment decisions, and monitoring treatment effects. For CTC-positive patients, more early aggressive treatment and effective evaluation may be required.

The CellSearch system used for detection of CTCs has more advantages compared to ICC and PCR, including saving time and cost, easy operation and higher specificity and reproducibility for CTC enrichment. Since our meta-analysis of researches utilizing the CellSearch system for detection of CTCs decreased the heterogeneity caused by various detection assays, there was no statistical significance in between-study heterogeneity for OS and RFS. Therefore, the detection method is the main source of between-study heterogeneity. In all comparisons, shape of the funnel plots had a symmetrical distribution. Thus, no significant publication bias was found in the meta-analyses of OS and RFS.

In addition, clinical consensus still remained equivocal on the optimal cutoff value for predicting the prognosis of EC patients with CTCs. In our meta-analysis, both the cut-off value CTCs $\geq 1 / 7.5 \mathrm{ml}$ and CTCs $\geq 2 / 7.5 \mathrm{ml}$ seemed to indicate equivalent predicative value, suggesting these two cut-off values are both associated with poor prognosis. However, when we excluded the intratherapy set of Tanaka et al., a significantly higher HR for OS was found with the cut-off value of CTCs $\geq 2 / 7.5 \mathrm{ml}$ $(\mathrm{HR}=3.14,95 \% \mathrm{CI}: 1.82-11.97)$ than with the cut-off value of CTCs $\geq 1 / 7.5 \mathrm{ml}$ (HR $=2.89,95 \% \mathrm{CI}: 1.93,4.31$ ). Therefore, in EC patients, the cut-off value of CTCs $\geq 2$ / $7.5 \mathrm{ml}$ may be correlated with poorer prognosis than the cut-off value of CTCs $\geq 1 / 7.5 \mathrm{ml}$. Thus, high-quality, well-designed, large-scale multi-centre research is needed to identify the better cut-off value and more appropriate sampling time of CTC detection.

Several limitations remained in our study. First, due to several studies didn't report HRs, the estimated HR was used to assess prognostic effects based on the method described by Tierney et al. [21]. Second, we used extracted data rather than raw data from individual patients, and we could not correct all clinicopathological parameters according to a consistent standard. Third, we limited our analysis to studies published in English, so the choice of language brings another bias. Fourth, the total amount of patients was relatively small in the meta-analysis. Fourth, there are low patients' number and no multicenter controlled trials in our metaanalysis. Fifth, with the limited data in the included articles, the data considering clinical pathological characteristics and prognosis of AC and SCC group patients were not available separately. Despite these limitations, we still demonstrated that CTC positivity determined using CellSearch system was an indicator of poor prognosis in patients with EC.

\section{Conclusions}

Sum up, our meta-analysis indicated that the presence of CTCs determined using the CellSearch system is correlated with the prognosis of EC patients and provided a scientific foundation for EC staging. Additionally, subgroup analysis indicated that CTC positivity is more associated with a poorer prognosis than CTC negativity. Additionally, the CTCs determined using the CellSearch system can be regarded as an effective evaluation tool for assessing chemoradiotherapy efficacy and monitoring tumour recurrence for EC patients. However, highquality, well-designed, large-scale multi-centre research is needed to verify our results and confirm the clinical value of CTCs determined using the CellSearch system in EC patients.

\section{Abbreviations}

EC: Esophageal carcinoma; CTCs: Circulating tumor cells; PB: Peripheral blood; SCC: Squamous cell carcinoma; AC: Adenocarcinoma; ORs: Odds ratios; RRs: Risk ratios; HRs: Hazard ratios; Cis: Confidence intervals; OS: Overall survival; RFS: Relapse-free survival; NOS: Newcastle-Ottawa Scale;

DCR: Disease control rate; CR: Complete response; PR: Partial response; SD: Stable disease; PD: Progressive disease; ORR: Overall response rate 


\section{Acknowledgments}

The author would like to thank Zhou Wei, PhD, employees of State key Laboratory of Cancer Biology and National Clinical Research Center for Digestive Diseases, for performing the literature search, developing the first draft and analyzing data.

\section{Authors' contributions}

LYD and WGL conceived and designed the study. WGL, YWL and WXQ searched literatures. LYD, DLL and NLR selected studies. WGL, ZYJ and LJQ extracted data. LYD, WGL performed outcome analysis. LYD, WGL wrote the paper. WGL, YWL, WXQ, HL and FDM reviewed and edited the manuscript. All authors read and approved the manuscript.

\section{Funding}

This project was supported by The grant of Shaanxi Province (No. 2019ZDLSF01-02-01; 2018SF-240) and Xjijng Zhutui Project. The funding bodies played no role in the design of the study and collection, analysis, and interpretation of data and in writing the manuscript.

\section{Availability of data and materials}

The datasets used and/or analysed during the current study available from the corresponding author on reasonable request.

\section{Ethics approval and consent to participate}

Not applicable.

\section{Consent for publication}

Not applicable.

\section{Competing interests}

The authors declare that they have no competing interests.

\section{Author details}

'State key Laboratory of Cancer Biology and National Clinical Research Center for Digestive Diseases, Xijing Hospital of Digestive Diseases, Fourth Military Medical University, 127 Changle West Road, Xi'an, Shaanxi Province 710032, PR China. ${ }^{2}$ School of Aerospace Medicine, Fourth Military Medical University, Xi'an 710032, China.

Received: 31 March 2020 Accepted: 10 June 2020

Published online: 22 June 2020

\section{References}

1. Arnal MJD, Arenas ÁF, Arbeloa ÁL. Esophageal cancer: Risk factors, screening and endoscopic treatment in Western and Eastern countries. World J Gastroenterol. 2015;21(26):15-25.

2. Bray F, Ferlay J, Soerjomataram I, Siegel RL, Torre LA, Jemal A. Global cancer statistics 2018: GLOBOCAN estimates of incidence and mortality worldwide for 36 cancers in 185 countries. CA Cancer J Clin. 2018;68(6):394-424.

3. Njei B, Mccarty TR, Birk JW. Trends in esophageal cancer survival in United States adults from 1973 to 2009: a SEER database analysis. J Gastroenterol Hepatol. 2016;31(6):1141-6.

4. Arnold M, Soerjomataram I, Ferlay J, Forman D. Global incidence of oesophageal cancer by histological subtype in 2012. Gut. 2015;64(3):381-7.

5. Godfrey TE, Raja S, Finkelstein SD, Gooding WE, Kelly LA, Luketich JD, et al. Prognostic value of quantitative reverse transcription-polymerase chain reaction in lymph node-negative esophageal cancer patients. Clin Cancer Res. 2001;7(12):4041-8.

6. Kijima F, Natsugoe S, Takao S, Aridome K, Baba M, Yoshifumi M, et al. Detection and clinical significance of lymph node micrometastasis determined by reverse transcription-polymerase chain reaction in patients with esophageal carcinoma. Oncology. 2000;58(1):38-44.

7. Sun N, Li X, Wang Z, Zhang R, Wang J, Wang K, et al. A multiscale TiO2 Nanorod Array for ultrasensitive capture of circulating tumor cells. ACS Appl Mater Interfaces. 2016;8(20):12638-43.

8. Ashworth TR. A case of cancer in which cells similar to those in the tumors were seen in the blood after death. Aust Med J. 1869:14:146-9.

9. Tsujiura M, Ichikawa D, Konishi H, Komatsu S, Shiozaki A, Otsuji E, et al. Liquid biopsy of gastric cancer patients: circulating tumor cells and cell-free nucleic acids. World J Gastroenterol. 2014;20(12):3265-86.
10. Shen Z, Wu A, Chen X. Current detection technologies for circulating tumor cells. Chem Soc Rev. 2017:46(8):2038-56.

11. Konczalla L, Ghadban T, Effenberger KE, Wostemeier A, Riethdorf S, Uzunoglu FG, et al. Prospective comparison of the prognostic relevance of circulating tumor cells in blood and disseminated tumor cells in bone marrow of a single Patient's cohort with esophageal Cancer. Ann Surg. 2019;7:1-7.

12. Woestemeier A, Ghadban T, Riethdorf S, Harms-Effenberger K, Konczalla L, Uzunoglu FG, et al. Absence of HER2 expression of circulating tumor cells in patients with non-metastatic esophageal Cancer. Anticancer Res. 2018; 38(10):5665-9.

13. Bettegowda C, Sausen M, Leary RJ, Kinde I, Wang Y, Agrawal N, et al. Detection of circulating tumor DNA in early- and late-stage human malignancies. Sci Transl Med. 2014;6(224):224ra24.

14. Swennenhuis JF, van Dalum G, Zeune LL, Terstappen LW. Improving the CellSearch ${ }^{\oplus}$ system. Expert Rev Mol Diagn. 2016;16(12):1291-305.

15. Janni WJ, Rack B, Terstappen LW, Pierga JY, Taran FA, Fehm T, et al. Pooled analysis of the prognostic relevance of circulating tumor cells in primary breast Cancer. Clin Cancer Res. 2016:22(10):2583-93.

16. Ma X, Xiao Z, Li X, Wang F, Zhang J, Zhou R, et al. Prognostic role of circulating tumor cells and disseminated tumor cells in patients with prostate cancer: a systematic review and meta-analysis. Tumour Biol. 2014; 35(6):5551-60.

17. Yang C, Zou K, Yuan Z, Guo T, Xiong B. Prognostic value of circulating tumor cells detected with the CellSearch System in patients with gastric cancer: evidence from a meta-analysis. Onco Targets Ther. 2018;11:1013-23.

18. Huang X, Gao P, Song Y, Sun J, Chen X, Zhao J, et al. Meta-analysis of the prognostic value of circulating tumor cells detected with the CellSearch System in colorectal cancer. BMC Cancer. 2015;15:202.

19. Stang A. Critical evaluation of the Newcastle-Ottawa scale for the assessment of the quality of nonrandomized studies in meta-analyses. Eur J Epidemiol. 2010;25(9):603-5.

20. Therasse P, Arbuck SG, Eisenhauer EA, Wanders J, Kaplan RS, Rubinstein L, et al. New guidelines to evaluate the response to treatment in solid tumors. European Organization for Research and Treatment of Cancer, National Cancer Institute of the United States, National Cancer Institute of Canada. J Natl Cancer Inst. 2000;92(3):205-16.

21. Tierney JF, Stewart LA, Ghersi D, Burdett S, Sydes MR. Practical methods for incorporating summary time-to-event data into meta-analysis. Trials. 2007;8:16.

22. Higgins JPT, Thompson SG. Quantifying heterogeneity in a meta-analysis. Stat Med. 2002;21(11):1539-58

23. Tanaka M, Takeuchi H, Osaki Y, Hiraiwa K, Nakamura R, Oyama T, et al. Prognostic significance of circulating tumor cells in patients with advanced esophageal cancer. Esophagus. 2015;12(4):352-9.

24. Matsushita D, Uenosono Y, Arigami T, Yanagita S, Nishizono Y, Hagihara T, et al. Clinical significance of circulating tumor cells in peripheral blood of patients with esophageal squamous cell carcinoma. Ann Surg Oncol. 2015; 22(11):3674-80

25. Reeh M, Effenberger KE, Koenig AM, Riethdorf S, Eichstadt D, Vettorazzi E, et al. Circulating tumor cells as a biomarker for preoperative prognostic staging in patients with esophageal Cancer. Ann Surg. 2015;261 (6):1124-30.

26. Sclafani F, Smyth E, Cunningham D, Chau I, Turner A, Watkins D. A pilot study assessing the incidence and clinical significance of circulating tumor cells in esophagogastric cancers. Clin Colorectal Cancer. 2014;13(2):94-9.

27. Hiraiwa K, Takeuchi H, Hasegawa H, Saikawa Y, Suda K, Ando T, et al. Clinical significance of circulating tumor cells in blood from patients with gastrointestinal cancers. Ann Surg Oncol. 2008;15(11):3092-100.

28. Rice TW, Apperson-Hansen C, DiPaola LM, Semple ME, Lerut TE, Orringer $M B$, et al. Worldwide esophageal Cancer collaboration: clinical staging data. Dis Esophagus. 2016;29(7):707-14.

29. Fidler IJ. The pathogenesis of cancer metastasis: the 'seed and soil' hypothesis revisited. Nat Rev Cancer. 2003;3(6):453-8.

30. Chaffer $\mathrm{CL}$, Weinberg RA. A perspective on cancer cell metastasis. Science. 2011:331(6024):1559-64.

31. Lu YJ, Wang P, Wang X, Peng J, Zhu YW, Shen N. The significant prognostic value of circulating tumor cells in triple-negative breast cancer: a metaanalysis. Oncotarget. 2016;7(24):37361-9.

32. Nicolazzo C, Busetto GM, Gradilone A, Sperduti I, Del Giudice F, Loreni F, et al. Circulating tumor cells identify patients with super-high-risk nonmuscle-invasive bladder Cancer: updated outcome analysis of a prospective single-center trial. Oncologist. 2019;24(5):612-6. 
33. Gao Y, Xi H, Wei B, Cui J, Zhang K, Li H, et al. Association between liquid biopsy and prognosis of gastric Cancer patients: a systematic review and meta-analysis. Front Oncol. 2019;9:1222.

34. Zhou Y, Bian B, Yuan X, Xie G, Ma Y, Shen L. Prognostic value of circulating tumor cells in ovarian Cancer: a meta-analysis. PLoS One. 2015;10(6): e0130873.

35. Hou J, Zou K, Yang C, Leng X, Xu Y. Clinicopathological and prognostic significance of circulating tumor cells in patients with esophageal cancer: a meta-analysis. Onco Targets Ther. 2018;11:8053-61.

36. de Wit S, van Dalum G, Lenferink AT, Tibbe AG, Hiltermann TJ, Groen HJ, et al. The detection of EpCAM(+) and EpCAM(-) circulating tumor cells. Sci Rep. 2015;5:12270.

37. de Wit S, Manicone M, Rossi E, Lampignano R, Yang L, Zill B, et al. EpCAM ${ }^{\text {high }}$ and EpCAM low circulating tumor cells in metastatic prostate and breast cancer patients. Oncotarget. 2018:9(86):35705-16.

38. de Wit S, Rossi E, Weber S, Tamminga M, Manicone M, Swennenhuis JF, et al. Single tube liquid biopsy for advanced non-small cell lung cancer. Int J Cancer. 2019;144(12):3127-37.

39. Nicolazzo C, Raimondi C, Francescangeli F, Ceccarelli S, Trenta P, Magri V, et al. EpCAM-expressing circulating tumor cells in colorectal cancer. Int J Biol Markers. 2017;32(4):e415-20.

40. Moon DH, Lindsay DP, Hong S, Wang AZ. Clinical indications for, and the future of, circulating tumor cells. Adv Drug Deliv Rev. 2018;125:143-50.

41. Riethdorf S, O'Flaherty L, Hille C, Pantel K. Clinical applications of the CellSearch platform in cancer patients. Adv Drug Deliv Rev. 2018;125:102-21.

42. Mohme M, Riethdorf S, Pantel K. Circulating and disseminated tumour cells - mechanisms of immune surveillance and escape. Nat Rev Clin Oncol. 2017;14(3):155-67.

43. Lindsay CR, Blackhall FH, Carmel A, Fernandez-Gutierrez F, Gazzaniga P, Groen HJM, et al. EPAC-lung: pooled analysis of circulating tumour cells in advanced non-small cell lung cancer. Eur J Cancer. 2019;117:60-8.

44. Zou K, Yang S, Zheng L, Wang S, Xiong B. Prognostic role of the circulating tumor cells detected by cytological methods in gastric Cancer: a metaanalysis. Biomed Res Int. 2016;2016:2765464.

45. Huang X, Gao P, Song Y, Sun J, Chen X, Zhao J, et al. Relationship between circulating tumor cells and tumor response in colorectal cancer patients treated with chemotherapy: a meta-analysis. BMC Cancer. 2014;14:976.

\section{Publisher's Note}

Springer Nature remains neutral with regard to jurisdictional claims in published maps and institutional affiliations.

Ready to submit your research? Choose BMC and benefit from:

- fast, convenient online submission

- thorough peer review by experienced researchers in your field

- rapid publication on acceptance

- support for research data, including large and complex data types

- gold Open Access which fosters wider collaboration and increased citations

- maximum visibility for your research: over $100 \mathrm{M}$ website views per year

At $\mathrm{BMC}$, research is always in progress.

Learn more biomedcentral.com/submissions 